\title{
Relationship between organizational trust and organizational citizenship behaviors: Staff nurses' perspective
}

\author{
Amal Diab Ghanem Atalla*1, Nevine Hassan Abdelaal ${ }^{2}$ \\ ${ }^{1}$ Nursing Administration Department, Faculty of Nursing, Alexandria University, Alexandria, Egypt \\ ${ }^{2}$ Nursing Administration Department, Faculty of Nursing, Damanhour University, Damanhour, Egypt
}

Received: June 1, 2019

DOI: $10.5430 /$ jnep.v9n11p10
Accepted: July 15, 2019

Online Published: August 5, 2019

URL: https://doi.org/10.5430/jnep.v9n11p10

\begin{abstract}
Background and objective: Individuals, who work in an organization where there is a high level of trust, perceive themselves as an important and valued part of this organization. With more enthusiasm, they come to work and are happier with their jobs. Thus, staff nurses' organizational trust, which forms the basis of intra-organizational relationships, can affect their performance and help them to demonstrate organizational citizenship behaviors. The aim of this study was to assess organizational trust and organizational citizenship behaviors from staff nurses' perspective. Also, to investigate the relationship between organizational trust and organizational citizenship behaviors at Alexandria Main University Hospital.

Methods: A descriptive correlational design was utilized with convenient sample of staff nurses $(\mathrm{n}=352)$ including staff nurses who works in units of medical care $(n=90)$, in units of surgical care $(n=120)$, and in critical care units $(n=142)$. Two tools were used to measure the study variables: Tool I: Organizational Trust Inventory (OTI). Tool II: Organizational Citizenship Behavior Scale (OCBS).

Results: The highest mean score of organizational trust was related to trust in managers, while, the lowest mean score was related to trust in organization. The highest mean score of organizational citizenship behaviors was related to conscientiousness, while the lowest mean score was related to sportsmanship.

Conclusions and recommendations: Staff nurses perceived high organizational trust and moderate organizational citizenship behaviors. There is a strong positive high significant correlation between overall organizational trust and overall organizational citizenship behaviors as perceived by staff nurses. Continuous periodic training programs should be given for staff nurses in different healthcare units, to increase their awareness about organizational trust and how to demonstrate organizational citizenship behaviors.
\end{abstract}

Key Words: Organizational trust, Organizational citizenship behaviors, Staff nurses

\section{INTRODUCTION}

Trust is essential in all relationships shaped between the healthcare providers and their managers within any healthcare organization. ${ }^{[1]}$ Staff nurses are healthcare providers who have the most important role in any healthcare organization thus, their organizational trust is a vital constituent of their professional performance with promising outcomes for both the staff nurses and the overall organization. Health

\footnotetext{
*Correspondence: Amal Diab Ghanem Atalla; Email: aml.diab@alexu.edu.eg; Address: Nursing Administration Department, Faculty of Nursing, Alexandria University, Alexandria, Egypt.
} 
care managers pay specific attention in order to develop organizational trust among staff nurses and their co-workers to guarantee that all staff moves toward and achieves common goals. ${ }^{[1,2]}$

Organizational trust is defined as: A sense of commitment and confidence, without the experiences of fear, doubts and hesitation. Staff nurses believe that they will receive assistance and cooperation in solving problems in times of need, without hidden motives or negative thoughts on the part of others. ${ }^{[3]}$ Moreover, organizational trust is the belief of staff nurses as a whole, that organization will make every effort to act in harmony with commitments to safeguard honesty in relationships among healthcare providers. ${ }^{[4]}$ The involved staff nurses will not try to exploit others, even if they have such opportunities. ${ }^{[5]}$ In addition, organizational trust has been considered as "the method by which staff nurses feel the support that is offered by the organizational culture, and be confident in managers that they are honest and factual to their promises", $[6,7]$

Organizational trust which is perceived by staff nurses, includes three essential elements: Trust in co-workers, trust in managers and trust in organization. ${ }^{[8-11]}$ Trust in co-workers is the degree to which staff nurses are willing to build trustful relationships and have faith in their colleagues to work with them under any circumstances. ${ }^{[8,9,11]}$ Trust in managers: is the degree to which the staff nurses trust their supervisors and leaders after evaluating their leadership capabilities. ${ }^{[10,11]}$ Trust in organization is the degree to which staff nurses in different conditions comply and be highly confident in the culture and values created by the hospital top administration. They have the desire to believe in the hospital structures, processes, technical competencies and policies after overall evaluation of hospital values, beliefs, attitudes, decisions and outcomes. $^{[9,11]}$

In a healthcare system, staff nurses' organizational trust fosters the multidisciplinary approach with good communication, collaboration, and teamwork. ${ }^{[12]}$ This will encourage the healthcare providers, especially staff nurses to demonstrate frequent organizational citizenship behaviors (OCBs). ${ }^{[13,14]}$

The concept of OCBs is defined as individual behaviors that are unrestricted. These behaviors are not explicitly or openly recognized by the formal system of rewards, and they mutually promote the organization's effective functioning. ${ }^{[8]}$ Furthermore, OCBs are flexible behaviors that are performed on the basis of choice. They are based not on directives or any perception of necessity, but on voluntary work and they are not also, a part of job description. ${ }^{[9]}$ There are five dimensions of OCBs that are very frequently documented in researches which include: altruism, courtesy, civic virtue, conscientiousness and sportsmanship. ${ }^{[10-12]}$

Altruism in the workplace is about assisting and supporting behaviors that can be directed inside or outside the organization. The gathering of staff nurses' helping behaviors proves advantageous for the organization. ${ }^{[1,15-17]}$ Courtesy is defined as a flexible behavior that aims to avoid conflicts of work with other healthcare providers. Every staff nurse tries to prevent problems from arising, be polite and considerate others. ${ }^{[17,18]}$ Civic virtue is marked by behaviors that reflect the deep concerns and active interests of staff nurses in the organization's philosophy and value system. ${ }^{[15,19]}$ The conscientiousness includes obedience with respect to organizational rules and norms. It represents the trustworthiness and reliability of the organization's staff nurses. ${ }^{[17,20]}$ Finally, sportsmanship is defined as the tolerance of staff nurses to less than optimal organizational circumstances without complaining and massively blowing problems. It also, reveals the ability of staff nurses to adapt even if they do not like or agree with the changes taking place within the organization. ${ }^{[15,20]}$

\subsection{Problem statement and significance of the study}

In a healthcare delivery system, staff nurses are the healthcare professionals that most likely to quit. If staff nurses have no feeling of trust in co-workers, managers and organization, they will create a climate of resignation without any citizenship in their behaviors. This makes it hard to concentrate on agreed targets and organizational survival. Thus, staff nurses will be unsatisfied, provide healthcare services in a less efficient non creative way with more absenteeism. This result in reducing teamwork and success, inhibiting commitment to organization, diminishing motivation and competencies and decreasing staff nurses' OCBs.

The relationship between organizational trust and OCBs has been internationally studied in the literature. In India, a study was done by Singh \& Srivastava (2016) to assess the relationship between organizational trust and OCBs. It concluded that the presence of organizational trust is positively correlated with all the dimensions of OCBs as revealed by the members of the organization. ${ }^{[21]}$ Another study was done in Asia by Sendjaya et al. (2019) to assess how to foster OCBs in Asia: The mediating roles of trust and job satisfaction. They summarized that OCB was mediated by trust and more specifically, trust and job satisfaction are important factors in demonstrating OCBs. ${ }^{[22]}$

In Egypt, a study was done by Abed \& Elewa (2016) to assess the relationship between organizational support, work engagement and OCBs as perceived by staff nurses at different hospitals. The study confirmed that there was a highly 
significant correlation between nurses' perception of organizational support, work engagement and OCBs. ${ }^{[23]}$

It seems very worthy, up to the current researchers' knowledge, there are no studies done in Egypt to examine the nature of the relationship between organizational trust and OCBs. There is a lack of in-depth researches and little is known whether staff nurses' demonstration of OCBs is correlated to their perception of organizational trust, with regard to the Egyptian hospitals' context. Hence, such this relationship needs to be researched. This research will help to clarify the nature of the relationship between the two constructs, it will also point out areas for future research that are needed in this research topic.

\subsection{The aim of the study}

The aim of this study was to assess organizational trust and organizational citizenship behaviors from staff nurses' perspective at Alexandria Main University Hospital. Further, to investigate the relationship between organizational trust and organizational citizenship behaviors at Alexandria Main University Hospital.

\subsection{Research question}

With this in mind the following research questions are postulated: 1 . What is the staff nurses' perspective of organizational trust and organizational citizenship behaviors at Alexandria Main University Hospital? 2. What is the relationship between organizational trust and organizational citizenship behaviors from staff nurses' perspective at Alexandria Main University Hospital?

\section{MATERIALS AND METHOD}

\subsection{Research design and setting}

A descriptive correlational design was used. The current study was executed in all inpatient units of medical, surgical and critical care at Alexandria Main University Hospital. It is a university hospital equipped with 1,825 beds. The capacity of medical care units and its specialties is 952 beds, while surgical care units and its specialties include 773 beds and critical care units include 100 beds. Medical care units and its specialties include 25 units, while, surgical care units and its specialties include 17 units and critical care units include 13 units. Alexandria Main University Hospital is the largest teaching hospital affiliated to Alexandria city. It provides wide range of services to all populations from Alexandria and other governorates such as: Emergency services, medical, surgical and critical care services, radiological investigations department, pharmacy, laboratory, physiotherapy, outpatients and Para-medical services such as: Dietary, maintenance, etc. Moreover, it provides teaching and clinical training services for medical and nursing students and setting for wide range of scientific researches.

\subsection{Subjects}

The subjects of the study included a non-probability convenience sample of staff nurses who are working in the previously mentioned units with experience more than six months and who will be available during the time of data collection and interested to participate in this study $(\mathrm{n}=352)$. They had been classified as follows: Staff nurses who are working in medical care units $(n=90)$, in surgical care units $(n=120)$, and in critical care units $(n=142)$ based on Power Analysis as follows:

(1) Total population of staff nurses $\mathrm{N}=750$.

(2) Acceptable error $=5 \%$;

(3) Expected Frequency 50\%;

(4) Epi-Info Program denotes the confidence coefficient at $99 \%$ with sample size $(n=352)$.

\subsection{Study measurement tools}

Two tools were used in the current study:

\subsubsection{Organizational Trust Inventory (OTI)}

It was developed by Altuntas (2008) ${ }^{[11]}$ and composed of 43 items and then updated by Celep and Yilmazturk (2012) ${ }^{[8]}$ to 36 items to measure staff nurses' organizational trust. The OTI is classified into three dimensions namely: Trust in coworkers, trust in managers and trust in organization. Each dimension composed of 12 items. The response will be measured on five points Likert - scale ranging from 1 to 5 as 1 $=$ strongly disagree and $5=$ strongly agree. The reversed score was applied for negative statements. The overall score ranged from 36 to 180 . Lower scoring of organizational trust ranged from 36 to $<85$, moderate scoring ranged from 85 to $<133$ and higher scoring ranged from 133 to 180 . The higher scoring indicates more positive perception of staff nurses about organizational trust.

\subsubsection{Organizational Citizenship Behavior Scale (OCBS)}

It was developed by Altuntas (2008) ${ }^{[11]}$ and composed of 24 items and then updated by Kumar and Shah (2015) ${ }^{[18]}$ to 15 items to determine how frequently the staff nurses demonstrate OCBs in the hospital. The OCBS is classified into five dimensions as follows: Altruism, courtesy, civic virtue, conscientiousness and sportsmanship. Each dimension composed of three items. The response will be measured on five points Likert-scale ranging from 1 to 5 where 1 indicate never and 5 indicate very often. The reversed score was applied for negative statements. The overall score ranged from 15 to 75 . Lower scoring of OCBs ranged from 15 to $<36$, moderate scoring ranged from 36 to $<56$ and higher scoring ranged 
from 56 to 75 . The higher scoring indicates more positive perception of staff nurses about OCBs.

In addition, staff nurses' demographic and work-related characteristics such as questions related to their gender, age, current working unit, educational qualifications, years of experience were also included.

\subsection{Method}

A formal permission has been obtained from the authoritative authorities of the Faculty of Nursing, Alexandria and Damanhour University and from the hospital and nursing director of Alexandria Main University Hospital to conduct the current study.

\subsection{Validity and reliability}

The two tools were adapted, translated into Arabic and submitted to a panel of five experts, three professors from the Faculty of Nursing, Alexandria University and two professors from the Faculty of Nursing, Damanhour University to review and test content validity, to give their suggestions and recommendations regarding the tools' contents, the nature of questions, clarity of items. Their comments are taken into consideration for ensuring accuracy and minimizing potential threats to validity of the study. Also, study tools were examined for reliability by measuring the internal consistency of items using Cronbach's alpha coefficient test. The two tools were proved to be reliable where $\alpha=0.91$ for the tool one (OTI) and 0.89 for tool two (OCBS) at a statistical significance level $p \leq .05$. The pilot study was carried out on $10 \%$ of staff nurses $(n=35)$ from previously mentioned setting in order to check and ensure clarity and feasibility of items, identify barriers and issues that may arise during data collection and to test needed time for filling the tools. Some items required clarification from researchers with no modification needed. The study sample did not include those who shared in the pilot study.

\subsection{Data collection}

Data were collected by the researchers using the study questionnaires which were distributed individually to staff nurses. Each nurse took approximately 20 minutes to complete all the questionnaires. Data collection took a period of three months starting from the first of November 2018 to the end of January 2019. All questions were answered and explanations were given accordingly.

\subsection{Ethical considerations}

The ethical committee of the faculty of Nursing, Alexandria University, Damanhour University approved the study protocol. An Informed written consent was obtained from the study subjects after explanation of the aim of the study. The confidentiality and anonymity were assured through assigning a code number for each staff nurse instead of names to protect their privacy. The right to withdraw from the study has been guaranteed at any time. Staff nurses were assured that data are confidential and used only for research purposes.

\subsection{Data analysis}

The researchers coded the data and fed it to the statistical package of social science (IBM SPSS), version 22. Frequency and percentages were used to describe demographics and work-related characteristics. Arithmetic mean and standard deviation (SD) were used for quantifying the studied variables (descriptive statistics). Pearson correlation coefficient analysis $(r)$ was used to test the nature of the relationship between organizational trust and organizational citizenship behaviors as perceived by staff nurses in the hospital (inferential statistics). All statistical analyses were performed using an alpha error of $p \leq .05$.

\section{Results}

Table 1 showed that about three-quarters of the staff nurses (79\%) were female. Nearly three-quarters of them (73.6\%) had been in the age group ranging from 30 to $<40$ years old. This table also illustrated that $40.3 \%$ of staff nurses were working in critical care units. Slightly less than one-half of them (47.2\%) have Diploma Nursing while slightly less than one third of them (30.1\%) have BSCN. Regarding the years of experience in the current working unit, $57.7 \%$ of staff nurses had years of experience ranging from 5 to $<10$ years.

As prominent in Table 2, the highest mean score of organizational trust as perceived by staff nurses was related to trust in managers $(55.40 \pm 5.94)$, while, the lowest mean score was related to trust in organization $(37.89 \pm 5.47)$. In addition, the overall mean score of organizational trust as perceived by staff nurses was $135.7 \pm 11.33$. This indicates that staff nurses perceived high organizational trust.

Table 3 illustrated that the highest mean score of OCBs as perceived by staff nurses was related to conscientiousness $(14.63 \pm 1.20)$, while, the lowest mean score was related to sportsmanship (6.34 \pm 1.52$)$. Also, the overall mean score of OCBs as perceived by staff nurses was $50.34 \pm 3.02$. This indicates that staff nurses perceived moderate organizational citizenship behaviors.

As evident in Table 4, there were high significant differences between all dimensions of organizational trust and organizational citizenship behaviors as perceived by staff nurses $(p<$ .001). Moreover, there was a strong positive high significant correlation between overall organizational trust and overall organizational citizenship behaviors as perceived by staff 
nurses $(r=0.778, p<.001)$.

Table 1. Demographic characteristics of staff nurses $(n=$ 352)

\begin{tabular}{|c|c|c|}
\hline Demographic characteristics & No. & $\%$ \\
\hline \multicolumn{3}{|l|}{ Gender } \\
\hline Male & 74 & 21.0 \\
\hline Female & 278 & 79.0 \\
\hline \multicolumn{3}{|l|}{ Age (Years) } \\
\hline$<30$ & 49 & 13.9 \\
\hline $30-<40$ & 259 & 73.6 \\
\hline $41-<50$ & 44 & 12.5 \\
\hline$\geq 50$ & 0 & 0.0 \\
\hline Mean \pm SD & \multicolumn{2}{|c|}{$34.97 \pm 6.02$} \\
\hline \multicolumn{3}{|l|}{ Current working unit } \\
\hline Critical care units & 142 & 40.3 \\
\hline Medical & 120 & 34.1 \\
\hline Surgical & 90 & 25.6 \\
\hline \multicolumn{3}{|l|}{ Educational qualifications } \\
\hline Bachelor science in Nursing (BSCN) & 106 & 30.1 \\
\hline Technical Nursing Institute & 80 & 22.7 \\
\hline Diploma Nursing & 166 & 47.2 \\
\hline Others & 0 & 0.0 \\
\hline \multicolumn{3}{|c|}{ Years of experience in the current working unit } \\
\hline$<5$ & 52 & 14.7 \\
\hline $5-<10$ & 203 & 57.7 \\
\hline $11-<20$ & 63 & 17.9 \\
\hline$\geq 20$ & 34 & 9.7 \\
\hline Mean \pm SD. & \multicolumn{2}{|c|}{$9.88 \pm 6.44$} \\
\hline
\end{tabular}

Table 2. Mean scores of organizational trust: Staff nurses' Perspective $(\mathrm{n}=352)$

\begin{tabular}{lll}
\hline Organizational Trust & Min.-Max. & Mean \pm SD. \\
\hline A. Trust in coworkers & $36.0-49.0$ & $42.44 \pm 5.83$ \\
C. Trust in managers & $35.0-60.0$ & $55.40 \pm 5.94$ \\
B. Trust in organization & $24.0-51.0$ & $37.89 \pm 5.47$ \\
Overall score & $112.0-157.0$ & $135.7 \pm 11.33$ \\
\hline
\end{tabular}

Table 3. Mean scores of organizational citizenship behaviors (OCBs): Staff nurses' Perspective $(n=352)$

\begin{tabular}{lll}
\hline $\begin{array}{l}\text { Organizational Citizenship } \\
\text { Behaviors (OCBS) }\end{array}$ & Min.-Max. & Mean \pm SD. \\
\hline A. Altruism & $9.0-13.0$ & $10.30 \pm 1.19$ \\
B. Courtesy & $9.0-12.0$ & $10.70 \pm 1.37$ \\
C. Civic virtue & $6.0-12.0$ & $8.37 \pm 1.03$ \\
D. Conscientiousness & $9.0-15.0$ & $14.63 \pm 1.20$ \\
E. Sportsmanship & $3.0-12.0$ & $6.34 \pm 1.52$ \\
Overall score & $41.0-60.0$ & $50.34 \pm 3.02$ \\
\hline
\end{tabular}

\section{Discussion}

Organizational trust is a crucial component of a healthy working environment. Successful relationships and attitudes that are settled by the staff nurses with the presence of organizational trust have several advantages and favorable outcomes within the healthcare organizations. When staff nurses trust in their co-workers, managers and organizations, they reveal more cooperative, supportive, and tolerant performance and demonstrate OCBs that reach their goals effectively and efficiently. ${ }^{[1,10]}$

Table 4. Correlation matrix ( $r$ ) between organizational trust and organizational citizenship behaviors scale (OCBs): Staff nurses' Perspective

\begin{tabular}{|c|c|c|c|c|c|}
\hline \multirow{2}{*}{$\begin{array}{l}\text { Organizational Citizenship } \\
\text { Behaviors Scale (OCBs) }\end{array}$} & & \multicolumn{4}{|l|}{ Organizational Trust } \\
\hline & & A. Trust in coworkers & C. Trust in managers & B. Trust in organization & Overall \\
\hline \multirow{2}{*}{ A. Altruism } & $R$ & 0.404 & 0.534 & 0.481 & 0.624 \\
\hline & $P$ & $<.001 * *$ & $<.001 * *$ & $<.001 * *$ & $<.001 * *$ \\
\hline \multirow{2}{*}{ B. Courtesy } & $R$ & 0.242 & 0.229 & 0.327 & 0.348 \\
\hline & $P$ & $<.001 * *$ & $<.001 * *$ & $<.001 * *$ & $<.001 * *$ \\
\hline \multirow{2}{*}{ C. Civic virtue } & $R$ & 0.226 & 0.269 & 0.507 & 0.435 \\
\hline & $P$ & $<.001 * *$ & $<.001 * *$ & $<.001 * *$ & $<.001^{* *}$ \\
\hline \multirow{2}{*}{ D. Conscientiousness } & $R$ & 0.331 & 0.460 & 0.478 & 0.556 \\
\hline & $P$ & $<.001 * *$ & $<.001 * *$ & $<.001 * *$ & $<.001 * *$ \\
\hline \multirow{2}{*}{ E. Sportsmanship } & $R$ & 0.256 & 0.362 & 0.202 & 0.363 \\
\hline & $P$ & $<.001 * *$ & $<.001 * *$ & $<.001 * *$ & $<.001 * *$ \\
\hline \multirow{2}{*}{ Overall } & $R$ & 0.487 & 0.626 & 0.663 & 0.778 \\
\hline & $P$ & $<.001 * *$ & $<.001 * *$ & $<.001 * *$ & $<.001^{* *}$ \\
\hline
\end{tabular}

${ }^{*} p \leq .05 ;{ }^{* *} p \leq .001 ; r=$ Person coefficient value: weak from 0.0 to 0.25 ; moderate from $>0.25$ to 0.5 ; strong from $>0.5$ to 1.00 . 
The present study revealed that staff nurses perceived high score of overall organizational trust as well as the highest mean score of organizational trust as perceived by staff nurses was related to trust in managers. This could be due to that the nurse manager is concerned with staff nurses' satisfaction and encouraging them to maintain more reciprocal respectful relationships. Also, their managers act in accordance with previously given promises, appreciate their extra efforts and are ready to listen to them whenever needed. In addition, this could be related to the fact that staff nurses worked within the same environment with their nurse managers who treated them with more respect. Another cause can be regarded as that staff nurses had a lot in common and more shared involvements and experiences with their unit managers and supervisors in the current working units, that resulted in positive interaction and trusty relationships. They therefore, have higher trust in their managers.

This result is consistent with Top et al. (2015) who showed that the level of confidence of nurses in their managers was above the average level as the managers respect and encourage staff to participate in decisions. ${ }^{[24]}$ Likewise, Ozer (2011) reported that nearly two thirds of the nurses had managers who could build a sense of trust in them when they manage by leading and directing. ${ }^{[25]}$

On the other hand, the lowest mean score of the organizational trust as perceived by staff nurses was related to trust in organization. This might be due to that knowledge and information are rarely shared, the hospital is unfair in treating staff nurses and their ideas are not valued. This also can be regarded through autocratic management, limited connections and relationships between staff nurses and top organization's managers. This result is consistent with Baykal and Altuntas (2010) who confirmed that staff organizational trust in their organization decreases when there is an autocratic managerial structure, unwillingness of top managers to share information, lack of consideration or appreciation of top organization's managers for their subordinates, understaffing and excessive workload due to an inadequate number of staff nurses in the organization. ${ }^{[26]}$ In this respect, Green and Johnson (2015) confirmed that staff trust in their organizations is increased as they receive assistance and collaboration for problem solving in times of need and have fair distribution of duties. $^{[27]}$ Moreover, Miner- Rubino and Reed (2010) stated that staff nurses' higher levels of trust reported in healthcare organizations where there is more information sharing. ${ }^{[4]}$

Furthermore, the present study revealed that staff nurses perceived moderate score of overall OCBs. Moreover, the highest mean score of OCBs as perceived by staff nurse was related to conscientiousness. This result is anticipated as most staff nurses in this hospital obey organizational rules even when no one is observing their performance. They do not take extra or long breaks while on duty, they are very organized, plan effectively and their attendance at work is above the norm. This can be attributed to staff nurses' perception and ethical awareness that the nursing profession involves the health of human beings, any delay, negligence, disregard, and even a few mistakes can cause serious harm. They therefore work with the utmost caution and care. In addition, self-sacrifice is always a basic part of nursing attitude, which may have contributed to the highest score of conscientiousness.

This finding is in line with Ellershaw et al. (2016) who proved that conscientious nurses are task oriented and tend to get highly involved in their jobs. This means that those staff nurses are dependable, persistent and achievement oriented. ${ }^{[28]}$ Additionally, Davis et al. (2012) confirmed that conscientious staff nurses tend to be more organized, comprehensive and they plan effectively for their duties. ${ }^{[29]}$

In addition, the lowest mean score of organizational citizenship behaviors as perceived by staff nurses was related to sportsmanship. This might be due to their frequent complaint about undesired administrative conditions, such as: lack of training and development, obligation to work with inadequate materials and resources, frequent unresolved conflict and lack of motivation. Staff nurses were unable to resolve the issues they often complained about. They usually focus on what is wrong instead of the positive side of a situation and are less motivated to do the work.

In this respect, various studies such as: Blau et al. (2010), Hadjali \& Salimi (2012), Pradhan (2016) and Yu et al. (2018) emphasized that lack of sportsmanship may result from the following factors: lack of specific job descriptions, absence of teamwork, frequent conflicts among team members during their communication, employment staff with insufficient skills and training, obligation to work with insufficient materials, hard working conditions, excessive working hours, inability to enjoy legal rights, insufficient wages, and lack of safety measures. ${ }^{[30-33]}$

Moreover, this study showed a strong positive high significant correlation between overall organizational trust and overall OCBs as perceived by staff nurses. This result can be justified that there had been a high significant difference between all dimensions of organizational trust and organizational citizenship behaviors. These findings are consistent with other studies which showed that organizational trust influence demonstration of OCBs by staff nurses. These studies investigate the relationships between organizational trust and OCBs and emphasized that The OCBs were demonstrated 
and exhibited by staff nurses who trusted their co-workers, managers and organizations. ${ }^{[34-40]}$

\section{Conclusion}

To sum up, based on the results of this study, staff nurses perceived high score of overall organizational trust and moderate score of overall organizational citizenship behaviors. Moreover, there was a strong positive high significant correlation between overall organizational trust and overall organizational citizenship behaviors as perceived by staff nurses.

\subsection{Strengths, limitations, and implications for future research}

The study contributes to investigate the relationship between organizational trust and organizational citizenship behaviors as perceived by staff nurses, this will increase the knowledge and behaviors of nursing leaders in order to improve organizational trust and in turn, organizational citizenship behaviors. It shed light on the strong significant correlation between the two variables. However, several limitations exist in this study. First, generalization is limited as the study was done only with staff nurses from one hospital. Second, the present study assessed only the relationship between staff nurses' perceptions of organizational citizenship behaviors as a dependent variable on their perception about organizational trust. Other variables that can affect organizational citizenship behaviors can be measured in future researches.

\subsection{Recommendations}

Some recommendations are highlighted in the light of the results of this study:

(1) Hospital administrative authorities should increase staff nurses' trust in the organization through conducting frequent meeting with them, sharing them in decisions, providing incentives and treating staff nurses with respect and fairness.

(2) Hospital administrative authorities should create a trustful work climate for staff nurses by communicating with them to identify and satisfy their needs.
(3) Nursing director as well as first level nurse managers should maintain trust among the staff nurses and their co-workers by encouraging teamwork, providing sufficient resources, managing conflict, providing recreational services and leading by discussion and democracy.

(4) Hospital should have suggestion box with maintaining anonymity in order to encourage staff nurses to express their needs and proposals for increasing their trust in the hospital.

(5) Hospital administrative authorities should foster staff nurses' sportsmanship through continuous emphasizing on: Improving performance more than just winning, giving positive reinforcement and keeping a sense of humor among staff nurses.

(6) Continuous periodic training programs should be given for staff nurses in order to increase their awareness about the importance of demonstrating organizational citizenship behaviors.

(7) Reward system should be introduced to the staff nurses who demonstrate organizational citizenship behaviors.

\subsection{Future researches}

- Replication of this study in a wider context of multiple hospitals to provide comparative design and facilitate generalization of the study findings.

- Including all health care providers not only staff nurses in the study for the generalization of findings.

\section{ACKNOWLEDgements}

Our deepest thanks to the hospital director and first level nurse managers of previously mentioned study units at Alexandria Main University Hospital for their support and encouragement. We are also, extremely grateful to staff nurses who participate in this study, for without them, this research would never have been completed.

\section{CONFlicts OF INTEREST Disclosure}

The authors declare that there is no conflict of interest.

\section{REFERENCES}

[1] McCabe T, Sambrook S. The antecedents, attributes and consequences of trust among nurses and nurse managers: A concept analysis. International Journal of Nursing Studies. 2014; 51(5): 815-827. PMid:24182730 https ://doi.org/10.1016/j.ijnurstu. 201 3.10 .003

[2] Jiang Z, Gollan P, Brooks G. Relationships between organizational justice, organizational trust and organizational commitment: A cross- cultural study of China, South Korea and Australia. The International Journal of Human Resource Management. 2017; 28(7): 973-1004. https://doi.org/10.1080/09585192.2015.1128457

[3] Bromiley P, Cummings L. Organizations with trust: A theoretical perspective. Research in Negotiations. 1995.

[4] Miner-Rubino K, Reed W. Testing a moderated mediational model of workgroup incivility: The roles of organizational trust and group regard. Journal of Applied Social Psychology. 2010; 40(12): 3148-69. 
https://doi.org/10.1111/j.1559-1816.2010.00695.x

[5] Alabrrow H, Ardakani M, Harooni A, et al. The relationship between organizational trust and organizational justice components and their role in job involvement in education. International Journal of Management Academy. 2013; 1(1): 25-41.

[6] Okello D, Gilson L. Exploring the influence of trust relationships on motivation in the health sector: a systematic review. Human Resources for Health. 2015; 13(1): 16. PMid:25889952 https: //doi.org/10.1186/s12960-015-0007-5

[7] Boies K, Fiset J, Gill H. Communication and trust are key: Unlocking the relationship between leadership and team performance and creativity. The Leadership Quarterly. 2015; 26(6): 1080-94. https://doi.org/10.1016/j.leaqua. 2015.07.007

[8] Celep C, Yilmazturk O. The relationship among organizational trust, multidimensional organizational commitment and perceived organizational support in educational organizations. Procedia-Social and Behavioral Sciences. 2012; 46: 5763-76. https ://doi.org/10.1 016/j.sbspro.2012.06.512

[9] Bahrami S, Hasanpour M, Rajaeepour S, et al. The relationship between organizational trust and nurse administrators' productivity in hospitals. Iranian Journal of Nursing and Midwifery Research. 2012; 17(6): 451.

[10] Chen S, Chang W, Lin C, et al. Organizational justice, trust, and identification and their effects on organizational commitment in hospital nursing staff. BMC Health Services Research. 2015; 15(1): 363. PMid:26347451 https://doi.org/10.1186/s12913-015-101 6-8

[11] Altuntas S. The relationship between nurses' organizational trust levels and their personal-professional characteristics and organizational citizenship behaviors. 2008; Unpublished doctoral thesis, Health Sciences Institute, Istanbul University, Istanbul, Turkey.

[12] Ostergaard L. Trust matters: A narrative literature review of the role of trust in health care systems in sub-Saharan Africa. Global Public Health. 2015; 10(9): 1046-59. PMid:25760634 https://doi.org/ 10.1080/17441692.2015.1019538

[13] Kaya S, Ileri Y, Yuceler A. Effects of organizational trust on identification in a university hospital in Turkey. Journal of Human Sciences. 2017; 14(2): 2014-20. https://doi.org/10.14687/jhs.v14i2 .4604

[14] Mullarkey M, Duffy A, Timmins F. Trust between nursing management and staff in critical care: a literature review. Nursing in Critical Care. 2011; 16(2): 85-91. PMid:21299761 https ://doi .org/10 $.1111 / j .1478-5153.2010 .00404 . x$

[15] Sharma J, Bajpai N, Holani U. Organizational citizenship behavior in public and private sector and its impact on job satisfaction: A comparative study in Indian perspective. International Journal of Business and Management. 2011; 6(1): 67. https ://doi .org/10 .5539/ijbm.v6n1p67

[16] Moideenkutty U. Moderating effect of supervisory role definitions and employee impression management on the relationship between organizational citizenship behavior and individual outcomes: a conceptual framework. Journal of Organizational Culture, Communications and Conflict. 2009; 13(1).

[17] Marinova SV, Cao XY, Park H. Constructive organizational values climate and organizational citizenship behaviors: A configurational view. Journal of Management. 2019; 45(5): 2045-71. https://doi.org/10.1177/0149206318755301

[18] Kumar M, Shah A. Psychometric Properties of Podsakoff's Organizational Citizenship Behaviour Scale in the Asian Context. The International Journal of Indian Psychology. 2015; 3(1): 51-60.

[19] Ocampo L, Acedillo V, Bacunador A, et al . A historical review of the development of organizational citizenship behavior (OCB) and its implications for the twenty-first century. Personnel Review. 2018; 47(4): 821-62. https://doi.org/10.1108/PR-04-2017-0136

[20] Lo M, Ramayah T. Dimensionality of organizational citizenship behavior (OCB) in a multicultural society: The case of Malaysia International Business Research. 2009; 2(1): 48-55. https ://doi . org/10.5539/ibr.v2n1p48

[21] Singh U, Srivastava K. Organizational Trust and Organizational Citizenship Behaviour. Global Business Review. 2016; 17(3): 594-609. https://doi.org/10.1177/0972150916630804

[22] Sendjaya S, Andre A, Brian P, et al. Fostering organisational citizenship behaviour in Asia: The mediating roles of trust and job satisfaction. In: Leading for High Performance in Asia. Springer, Singapore; 2019; 1-18. https://doi.org/10.1007/978-981-1 3-6074-9_1

[23] Abed F, Elewa A. The Relationship between Organizational Support, Work Engagement and Organizational Citizenship Behavior as Perceived by Staff Nurses at Different Hospitals. IOSR Journal of Nursing and Health Science (IOSR-JNHS) 2016; 5(4): 113-24.

[24] Top M, Akdere M, Tarcan M. Examining transformational leadership, job satisfaction, organizational commitment and organizational trust in Turkish hospitals: public servants versus private sector employees. The International Journal of Human Resource Management. 2015; 26(9): 1259-82. https://doi.org/10.1080/09585192.2 014.939987

[25] Ozer O, Zheng Y, Chen K. Trust in forecast information sharing Management Science. 2011; 57(6): 1111-37. https ://doi.org/ $10.1287 / \mathrm{mnsc} .1110 .1334$

[26] Baykal U, Altuntas S. Relationship between nurses' organizational trust levels and their organizational citizenship behaviors. Journal of Nursing Scholarship. 2010; 42(2): 186-194. PMid:20618602 https : //doi.org/10.1111/j.1547-5069.2010.01347.x

[27] Green B, Johnson C. Interprofessional collaboration in research, education, and clinical practice: working together for a better future. Journal of Chiropractic Education.2015; 29(1): 1-10. PMid:25594446 https://doi.org/10.7899/JCE-14-36

[28] Ellershaw J, Fullerton C, Rodwell J, et al. Conscientiousness, openness to experience and extraversion as predictors of nursing work performance: a facet-level analysis. Journal of Nursing Management. 2016; 24(2): 244-52. PMid:25939961 https://doi.org/10.111 $1 /$ jonm. 12306

[29] Davis S, Schrader V, Belcheir M. Influencers of ethical beliefs and the impact on moral distress and conscientious objection. Nursing Ethics. 2012; 19(6): 738-49. PMid:22736753 https ://doi.org/ 10.1177/0969733011423409

[30] Blau G, Moideenkutty U, Ingham K. Leader-member exchange as a significant correlate of organizational and occupational sportsmanship behaviors in a health services setting. Leadership in Health Services. 2010; 23(3): 219-32. https://doi .org/10.1108/1751 1871011061046

[31] Hadjali H, Salimi M. A study on organizational citizenship behaviors toward customer-orientation: a case of nursing home. International Journal of Academic Research. 2012; 4(4). https : //doi .org/10 $.7813 / 2075-4124.2012 / 4-4 /$ B. 20

[32] Pradhan P, Kaur T. Personality (Type A and Type B) In Relation to Organizational Citizenship Behaviour (OCB) Among Female Nursing Professionals. The International Journal of Indian Psychology. 2016; 4(1): 81-115.

[33] Yu H, Lou J, Eng C, et al. Organizational citizenship behaviour of men in nursing professions: Career stage perspectives. Collegian. 2018; 25(1): 19-26. https ://doi.org/10.1016/j. colegn. 201 7.02 .003 
[34] Lin S, Hsiao J. The relationships between transformational leadership, knowledge sharing, trust and organizational citizenship behavior. International Journal of Innovation, Management and Technology. 2014; 5(3): 171

[35] Andrade T, Estivalet V, Costa V, et al. Organizational citizenship behaviors trust and organizational support: Frame work analysis proposition. Revista Espacios. 2017; 38(4): 1-16.

[36] Mey M, Werner A, Theron A et al. The influence of perceptions of organizational trust and fairness on employee citizenship. Problems and Perspectives in Management. 2014; 12(3): 99-105.

[37] Lee H, Kim H, Hyuny Y. Determinants of organizational citizenship behavior and its outcomes. Global Business and Management Research. 2013; 5(1): 54.
[38] Yang Y. High-involvement human resource practices, affective commitment, and organizational citizenship behaviors. The Service Industries Journal. 2012; 32(8): 1209-27. https://doi.org/10.1 080/02642069.2010.545875

[39] Sjahruddin H, Normijati A. Personality effect on organizational citizenship behavior (OCB): trust in manager and organizational commitment mediator of organizational justice in Makassar City Hospitals (Indonesia). European Journal of Business and Management. 2013; 5(9): 95-104.

[40] Taghinezhad F, Safavi M, Raiesifar A ,et al .Antecedents of organizational citizenship behavior among Iranian nurses: a multicenter study. BMC Research Notes. 2015; 8(1): 547. PMid:26449980 https://doi.org/10.1186/s13104-015-1505-1 